\title{
Refrigerated Storage of Red Deer Epididymal Spermatozoa in the Epididymis, Diluted and with Vitamin C Supplementation
}

\author{
MR Fernández-Santos, AE Domínguez-Rebolledo, MC Esteso, JJ Garde and F Martínez-Pastor \\ Reproductive Biology Group, National Wildlife Research Institute (IREC), UCLM-CSIC-JCCM, and Game Research Institute (IDR), UCLM. \\ Albacete, Spain
}

\begin{abstract}
We have approached the problem of refrigerated storage of epididymal sperm samples from red deer by comparing three options: storing the genital (testicles within the scrotum), diluting the semen in extender or diluting the semen in extender supplemented with an anti-oxidant. Twenty-nine pairs of testes were collected. Spermatozoa from one of each of the pairs were immediately recovered, and diluted to $400 \times 10^{6} \mathrm{sperm} / \mathrm{ml}$ in Tris-citrate-fructose with $20 \%$ egg yolk. Control group was stored as such, and Anti-oxidant group was supplemented with $0.8 \mathrm{~mm}$ vitamin $\mathrm{C}$. The remaining epididymides and the diluted samples were stored at $5^{\circ} \mathrm{C}$ and spermatozoa were analysed at 0, 24, 96 and $192 \mathrm{~h}$ for: motility [computer-assisted semen analysis (CASA)], acrosomal integrity, sperm viability (eosine/nigrosine staining), normal tails 2 and chromatin status [sperm chromatin structure assay (SCSA)]. In general, seminal quality decreased with storage time. Vitamin C supported progressive motility better at $24 \mathrm{~h}$ (median $42 \%$ vs $23 \%$ Control and $15 \%$ epididymis), reduced the incidence of tail abnormalities and protected chromatin. Storing the semen in the epididymis slowed down motility loss, but slightly increased the occurrence of tail abnormalities and viability was lower at $192 \mathrm{~h}$. However, regarding chromatin status, sperm stored in the epididymis was protected similarly to those diluted in the medium supplemented with vitamin $\mathrm{C}$. Although the differences between the three groups were small, there were some advantages in supplementing the extender with vitamin $\mathrm{C}$. Besides, refrigerating the epididymis may be a good option when immediate processing is not available.
\end{abstract}

\section{Introduction}

The interest in preserving germ plasms of deer species has resulted in recent attention to the possible recovery, evaluation and preservation of sperms from the epididymides of dead animals (Zomborszky et al. 1999; Comizzoli et al. 2001; Hishinuma et al. 2003; Martinez-Pastor et al. 2006; Fernandez-Santos et al. 2007, 2007). Preservation of semen requires a reduction or arrest of the metabolism of spermatozoa, thereby prolonging their fertile life. This is commonly achieved by cryopreservation (Fernandez-Santos et al. 2006, 2007; Martinez-Pastor et al. 2006), but semen may also be stored in a liquid (unfrozen) state, using reduced temperatures or other means to depress metabolism (Maxwell and Salamon 1993). Despite the general agreement that only a few hours are enough to impair epididymal sperm, it has been shown that storage of epididymides at $5^{\circ} \mathrm{C}$ could be also a way of preserving sperm motility and fertilizing ability for several days (Kikuchi et al. 1998; Songsasen et al. 1998; An et al. 1999; Yu and Leibo 2002; Kaabi et al. 2003). Besides, there are several studies on this topic in red deer
(Martinez-Pastor et al. 2005, 2005). Moreover, Soler et al. (2003) concluded that red deer spermatozoa recovered from epididymides that had been stored at $5^{\circ} \mathrm{C}$ were of good quality, provided that storage time was less than $48 \mathrm{~h}$.

However, metabolism is not completely arrested during refrigerated storage, and spermatozoa may undergo irreversible reduction of motility, morphological integrity and fertility. These changes may be caused by the accumulation of toxic products of metabolism and, more importantly, of reactive oxygen species (ROS) formed through the univalent reduction of oxygen (e.g. superoxide anion, hydroxyl radical and hydrogen peroxide) (Misra and Fridovich 1972). This oxidative stress ends up causing structural damage to biomolecules and cellular components (Halliwell 1991). Oxidative damage may be increased in epididymal spermatozoa, since they are not exposed to the complex secretions of the accessory sex glands (seminal plasma), which are recognized as the predominant source of anti-oxidant protection for spermatozoa (Chen et al. 2003).

A wide array of enzyme scavengers and anti-oxidants has been used for blocking or preventing oxidative stress in a variety of cell systems. These anti-oxidants either scavenge ROS directly or prevent propagation of lipid peroxidation in cell membranes. A number of studies demonstrated the positive effect of adding ROS scavengers or anti-oxidants to liquid semen of ruminants for preservation at either 15 or $5^{\circ} \mathrm{C}$ (Maxwell and Stojanov 1996; Upreti et al. 1997, 1998). Vitamin C is a major chain-breaking anti-oxidant, being present in the extracellular fluid. It neutralizes hydroxyl, superoxide and hydrogen peroxide radicals and prevents sperm agglutination (Agarwal et al. 2004). Besides, Dawson et al. (1992) indicated an improvement in sperm viability, motility and maturity, along with a decrease in the percentage of abnormalities when increasing the dietary intake of ascorbic acid. Moreover, Vitamin C increases sperm counts in vivo in infertile male (Lewis et al. 1997), and it has been associated with fertility, may be having evolutionary significance (Millar 1992). Moreover, from a practical point of view, vitamin $\mathrm{C}$ is a component easy to find and cheaper than other anti-oxidants such as vitamin E or enzymatic ones (superoxide dismutase or 3 catalase). Thus, it is necessary to investigate which of the two options, whether the addition of vitamin $\mathrm{C}$ to the liquid storage or the maintenance of sperm within epididymides at $5^{\circ} \mathrm{C}$, would benefit the sperm preservation, in order to develop refrigeration protocols really adequate for red deer spermatozoa.

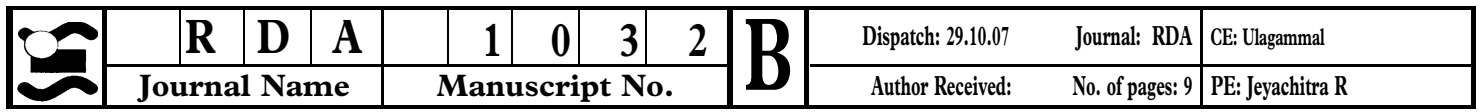


The main objective of the present study was to evaluate the refrigerated storage of epididymal red deer sperm under different conditions. Spermatozoa from one of each of the pairs were immediately recovered, evaluated and put on storage (control group). The remaining epididymides were cooled to $5^{\circ} \mathrm{C}$ and stored for 24,96 and $192 \mathrm{~h}$ (experimental groups), after which spermatozoa were collected and evaluated as in the control group. We have investigated the efficacies of three treatments; (1) Storing the genital (testicles and epididymes within the scrotum); (2) diluting the sperm sample in extender; (3) diluting the sperm sample in extender and supplementing with the anti-oxidant vita$\min \mathrm{C}$.

Storing the testicles instead of collecting the sperm sample is a common strategy when it is not possible to freeze the sample immediately, for instance, when harvesting takes place in the wild. Besides, we have interest on testing diluted storage with anti-oxidant supplementation, because the alternative strategy would be to extract the sample in the field and keep it diluted in extender until freezing is possible. Moreover, there are no other studies on the effect of anti-oxidants on red deer spermatozoa, apart from the one study by our group on cryopreserved semen (Fernandez-Santos et al. 2007).

\section{Materials and Methods}

All chemicals were of reagent grade and were purchased from Sigma or Merck (both of Madrid, Spain).

\section{Stags and testis collection}

For this study, we used spermatozoa recovered from the epididymides of 29 mature stags (age $>4.5$ years, weight $>130 \mathrm{~kg}$ ) that were legally culled and hunted in their natural habitat during the rutting season (September-October). Gamekeepers collected the complete male genitalia and provided the hour of the death. Hunting was in accordance with the harvest plan of the game reserve, which made following Spanish Harvest Regulation, Law 293 of Castilla-La Mancha, which conforms to European Union Regulation.

Immediately upon removal, the testes with attached epididymides were placed into plastic bags and transported to the laboratory at room temperature (approximately $22^{\circ} \mathrm{C}$ ) within $2 \mathrm{~h}$ after being removed.

\section{Experimental design}

Samples were processed as soon as they arrived at the laboratory. Spermatozoa were immediately collected from one epididymis of each pair of testicles according to the method described by Soler et al. (2003). Briefly, testes and epididymides were removed from the scrotal sac. Cauda epididymides were separated and the sperm mass was collected performing several cuts. The sperm samples were evaluated and split into two aliquots. One of the aliquots (Control) was diluted $\left(\sim 400 \times 10^{6} \mathrm{sperm} / \mathrm{ml}\right)$ in a modified Salamon's solution (Tris-citrate-fructose-egg yolk, TCF; see below). The other aliquot was diluted $\left(\sim 400 \times 10^{6} \mathrm{sperm} / \mathrm{ml}\right)$ in the same extender and supplemented with $0.8 \mathrm{~mm}$ of vita$\min \mathrm{C}$.

The remaining epididymides, still attached to the testicles, were put into plastic bags, and placed in beakers with water at $5^{\circ} \mathrm{C}$. The testicles and the diluted aliquots were stored at $5^{\circ} \mathrm{C}$ in the dark and evaluated at 24,96 or $192 \mathrm{~h}$ after sample processing. The aliquots were analysed at each sampling time; the stored testicles were divided in three groups, and each group was processed at one sampling time ( $24 \mathrm{~h}$ : eight testicles; 96 h: eight testicles; 192 h: 13 testicles), collecting the sperm and evaluating it.

Modified Salamon's solution contained Tris $(0.22 \mathrm{M})$, citric acid $(0.07 \mathrm{M})$ fructose $(0.05 \mathrm{M})$ and clarified egg yolk $(20 \% \mathrm{v} / \mathrm{v})$ (Fernandez-Santos et al. 2006). Clarified egg yolk was prepared as described by Holt et al. (1996). Briefly, fresh hen eggs were manually broken. Yolks were separated from the albumen and were carefully rolled on a filter paper to remove chalazae and traces of albumen adhering to the vitelline membrane. The latter was then disrupted with a scalpel blade and yolk was collected with a sterile syringe. Then, whole egg yolk was diluted in redistilled water $(1: 3)$ and centrifuged in sterile tubes at $10000 \times \mathrm{g}$ for $30 \mathrm{~min}$. After centrifugation, the pellet (granules) at the bottom of the tube was discarded and the water-soluble clear fraction (plasma) was saved to prepare the clarified EY-TCF medium.

\section{Sperm evaluation}

Motility was assessed immediately after recovery, and those samples having less than $30 \%$ individual motility were discarded.

\section{Sperm motility}

Sperm motility was determined with a computer-assisted motility analyzer (CASA system) using an optical phase contrast microscope (Nikon Eclipse 80i), equipped with negative phase contrast objectives and a warming stage at $37^{\circ} \mathrm{C}$, a Basler A302fs camera, and a $\mathrm{PC}$ with the Sperm Class Analyzer software (SCA2002; Microptic, Barcelona, Spain). A pre-warmed Makler counting chamber (10 $\mu \mathrm{m}$ depth) was loaded with $5 \mu \mathrm{l}$ of sample. The proportions of total (MT, \%) and progressively motile (MP, \%) spermatozoa, as well as kinematic parameters were recorded. Kinematic parameters were: velocity according to the actual path (VCL, $\mu \mathrm{m} / \mathrm{s}$ ), velocity according to the straight path (VSL, $\mu \mathrm{m} / \mathrm{s})$, velocity according to the average (smoothed) path (VAP, $\mu \mathrm{m} / \mathrm{s}$ ), linearity (LIN, \%), straightness (STR, \%), wobble (WOB, \%), amplitude of the lateral displacement of the sperm head (ALH, $\mu \mathrm{m})$ and frequency of the head beat (BCF, Hz). Sample acquisition rate was 25 images $/ \mathrm{s}$, and progressivity was defined as VCL $>25 \mu \mathrm{m} / \mathrm{s}$ and STR $>80 \%$. At least five fields per sample were recorded and analysed afterwards. We used VCL, LIN, $\mathrm{ALH}$ and BCF for this study.

\section{Acrosomal integrity}

Acrosomal integrity was evaluated after a $1: 20$ dilution in $2 \%$ glutaraldehyde, $0.165 \mathrm{M}$ cacodylate $\mathrm{HCl}$ buffer 
(pH 7.3). The percentage of spermatozoa with intact acrosomes ( $\%$ NAR) was assessed by phase-contrast microscopy at $\times 400$, after counting 100 cells.

\section{Sperm viability}

The sperm viability was also evaluated by using a nigrosine-eosine stain (NE). The NE stain was prepared as per method described Tamuli and Watson (1994). The diluted sperm $(5 \mu \mathrm{l})$ was mixed with the NE stain $(10 \mu \mathrm{l})$ at $37^{\circ} \mathrm{C}$, incubated for $30 \mathrm{~s}$, smeared and dried on a warm plate at $37^{\circ} \mathrm{C}$. The samples were evaluated using bright field microscopy at $\times 400$. Live spermatozoa remained unstained, whereas dead cells were dull pink. The percentage of live spermatozoa was expressed as viability (\%).

\section{Assessment of sperm chromatin stability}

Chromatin stability was assessed by staining with the metachromatic fluorescent dye acridine orange (AO), whose use is based on the susceptibility of sperm DNA to acid-induced denaturation in situ. AO shifts from green (dsDNA) to red (ssDNA) fluorescence depending on the degree of DNA denaturation (Evenson et al. 1980; Januskauska et al. 2001). Samples were diluted in TNE buffer $(0.01 \mathrm{M}$ Tris- $\mathrm{HCl}, 0.15 \mathrm{M} \mathrm{NaCl}, 1 \mathrm{~mm}$ EDTA, pH 7.4) to a final sperm concentration of $2 \times 10^{6}$ cells $\mathrm{ml}$ in cryotubes. Samples were dropped into LN2 and then allowed to thaw at room temperature. This process was repeated two more times and then frozen samples were stored in an ultra cold freezer at $-80^{\circ} \mathrm{C}$ until needed. For analysis, the samples were thawed on crushed ice. Acid-induced denaturation of DNA in situ was achieved by adding $0.4 \mathrm{ml}$ of an aciddetergent solution $(0.17 \%$ Triton $\mathrm{X}-100,0.15 \mathrm{M} \mathrm{NaCl}$, $0.08 \mathrm{~N} \mathrm{HCl}, \mathrm{pH} 1.4)$. After $30 \mathrm{~s}$, the cells were stained by adding $1.2 \mathrm{ml}$ of an acridine orange solution $(0.1 \mathrm{M}$ citric acid, 0.2 м Na2HPO4, 1mм EDTA, $0.15 \mathrm{~m} \mathrm{NaCl}$, $6 \mu \mathrm{g} / \mathrm{ml}$ acridine orange, $\mathrm{pH}$ 6.0). The stained samples were analysed by flow cytometry just 3 min after adding the acridine orange solution.

Samples were analysed on a FACScalibur flow cytometer (Becton Dickinson, San Jose, CA, USA), equipped with standard optics and an Ar-ion laser tuned at $488 \mathrm{~nm}$, and running at $200 \mathrm{~mW}$. Calibration was carried out using standard beads (Fluoresbrite plain YG $1.0 \mu \mathrm{M}$, Polysciencies Inc., Warrington, PA, USA). Green fluorescence was detected using the FL-1 photodetector (530/30 band pass filter) and red fluorescence with the FL-3 photodetector (650 long pass filter). Data were collected from 10000 events for further analysis with Cell-Quest software (Becton Dickinson). Sideward and forward scatter of light were recorded, so that only sperm cell-specific events were selected for analysis. Flow rate was 200 cells/s. At the beginning of each session, a standard semen sample was run through the cytometer, and settings were adjusted in order that mean fluorescence values $(0$ 1023 linear scale) for FL-1 and FL-3 were 475 and 125 respectively.

Results of the DNA denaturation test were processed to obtain the DFI (DNA fragmentation index; formerly called $\alpha \mathrm{t}$ ) for each spermatozoa, that express the shift from green to red fluorescence, and is expressed as the ratio of red fluorescence to total intensity of the fluorescence $[\mathrm{red}(\mathrm{red}+$ green $) \times 100]$. High values of DFI, indicates chromatin abnormalities. Flow cytometry data was processed with WinMDI software (Scripps Research Institute, La Jolla, CA, USA), and data was saved as tabbed text in order to obtain DFI and its derived indexes: standard deviation of DFI (SD-DFI), DFI\% ( $\%$ of spermatozoa with DFI > 25) HDS (High DNA Stainability; \% of spermatozoa with green fluorescence higher than 600 , of 1024 channels).

\section{Statistical analysis}

Statistical analyses were carried out using the $R$ 8 statistical package (http://www.r-project.org). Data were fitted to linear mixed-effect models by maximizing the log-likelihood (ML method) (Pinheiro and Bates 2000). Male was always included as random effect, and time (covariate) and treatment (factor with three levels: storage in the epididymis, in extender and in extender supplemented with vitamin C) were included as fixed factors, as expressed by the following formula:

$$
\begin{aligned}
Y_{i j k}=\mu+\text { Time }_{i}+\text { Treatment }_{j}+\text { Time }_{i} \times & \text { Treatment }_{j} \\
& + \text { Male }_{k}+\varepsilon_{i j k}
\end{aligned}
$$

For comparing treatments at a given time or between $0 \mathrm{~h}$ and sampling times, we used the contrasts provided by the analysis (adjusting p-values by Holm's correction for multiple comparisons).

\section{Results}

Table 1 shows the coefficients of the models tested and their significations. These coefficients describe the linear model (intercept and slope) for the Control treatment (sperm diluted in TCF and stored at $5^{\circ} \mathrm{C}$ ), and when the model is modified by the complementation with $0.8 \mathrm{~mm}$ vitamin $\mathrm{C}$ (vitamin $\mathrm{C}$ and time $\times$ vitamin $\mathrm{C}$ ), or sperm is kept in the epididymis (epididymis and time $\times$ epididymis).

All parameters related to sperm motility (Fig. 1) decreased with incubation time. Storing the samples diluted with a vitamin $\mathrm{C}$ supplemented medium (VitC) did not improved total motility, but it was better preserved keeping them into the epididymis. In fact, the model showed that VitC slightly accelerated the loss of motility regarding to samples stored diluted without supplementation (Control), whereas it was slowed down when kept into the epididymis (EP). Interestingly, at $24 \mathrm{~h}$ motility was lower in samples from stored epididymes, but it was higher for these samples at 96 and $192 \mathrm{~h}$. However, progressive motility was clearly higher for VitC at $24 \mathrm{~h}$, as showed by the main effects value. Nevertheless, at $192 \mathrm{~h}$ there were very low progressive motility because of low total motility, velocity and linearity. For the rest of motility parameters we did not find any effect of treatments in the model. However, VitC seemed to better preserve linear movement at the 
Table 1. Coefficients for the tested models and their significations (see the model formula and explanation in the statistic analysis section). The Intercept represents the theoric value of the model for the Control treatment at $0 \mathrm{~h}$, and time is the slope of the model for the control treatment along time. The values under Vitamin $\mathrm{C}$ and Epididymis would affect the value of the intercept for these treatments, while the interactions (time $\times$ vitamin $\mathrm{C}$ and time $\times$ epididymis) indicate if the parameter increased or decreased faster than the Control (affecting time, the slope of the model). The signification symbols indicate that the corresponding coefficient is statistically different from 0

\begin{tabular}{|c|c|c|c|c|c|c|}
\hline Parameter & Intercept & Time & Vitamin C & Epididymis & Time $\times$ vitamin $\mathrm{C}$ & Time $\times$ epididymis \\
\hline MT\% & $79.375^{* * *}$ & $-0.347 * * *$ & 3.042 & -2.707 & $-0.069 *$ & $0.076^{*}$ \\
\hline $\mathrm{MP} \%$ & $23.122 * * *$ & $-0.118 * * *$ & $8.376^{* * *}$ & -2.143 & $-0.049 *$ & -0.004 \\
\hline VCL & $91.889^{* * *}$ & $-0.269 * * *$ & -3.512 & -1.149 & -0.044 & 0.036 \\
\hline LIN & $40.123 * * *$ & $-0.070^{* *}$ & 8.781 & -2.109 & -0.062 & -0.036 \\
\hline ALH & $4.018 * * *$ & $-0.010 * *$ & -0.528 & -0.496 & 0.000 & 0.001 \\
\hline $\mathrm{BCF}$ & $8.152 * * *$ & $-0.018 * * *$ & -0.292 & 0.804 & 0.004 & -0.012 \\
\hline NAR & $95.718 * * *$ & $-0.026 * * *$ & 0.164 & -0.030 & -0.011 & -0.016 \\
\hline Viability & $91.374 * * *$ & 0.012 & 1.496 & 1.258 & -0.009 & $-0.098 * * *$ \\
\hline Normal tail & $92.177 * * *$ & $-0.063 * * *$ & -0.171 & 2.803 & $0.036^{* *}$ & $-0.044 * *$ \\
\hline SDDFI & 0.875 & $0.035^{* * *}$ & 0.340 & 1.305 & $-0.024 * *$ & $-0.029 * * *$ \\
\hline DFI $\%$ & -0.181 & $0.052 * * *$ & 0.355 & 0.908 & $-0.039 * *$ & $-0.046^{* *}$ \\
\hline HDS $\%$ & $6.214 * * *$ & $-0.023^{* *}$ & $-2.287^{*}$ & $-3.749 * *$ & 0.015 & $0.042 * * *$ \\
\hline
\end{tabular}

Signification symbols indicate that the corresponding coefficient is different from 0 : * $\mathrm{p}<0.05 ; * \mathrm{p}<0.01 ; * * \mathrm{p}<0.001$
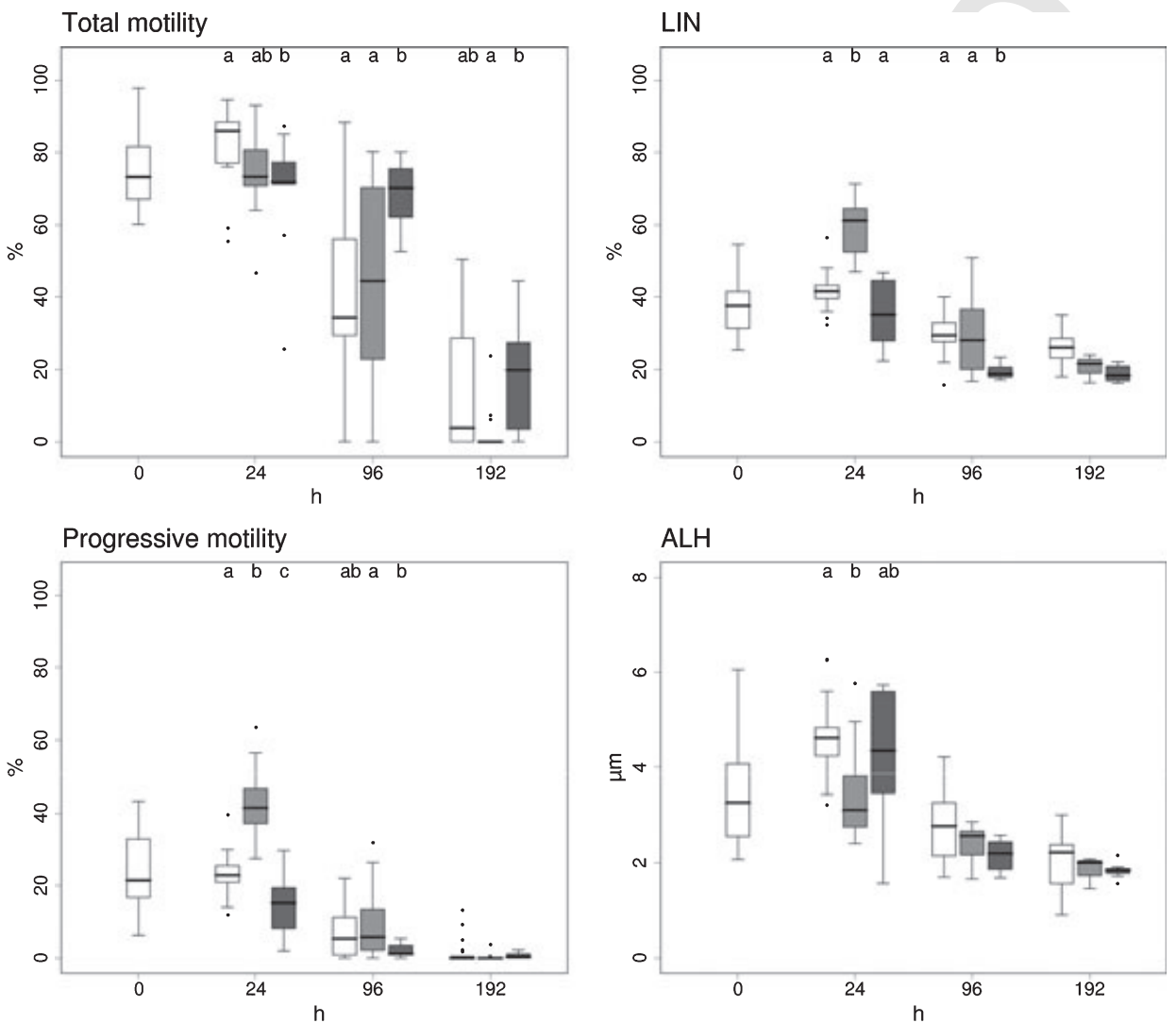

VCL
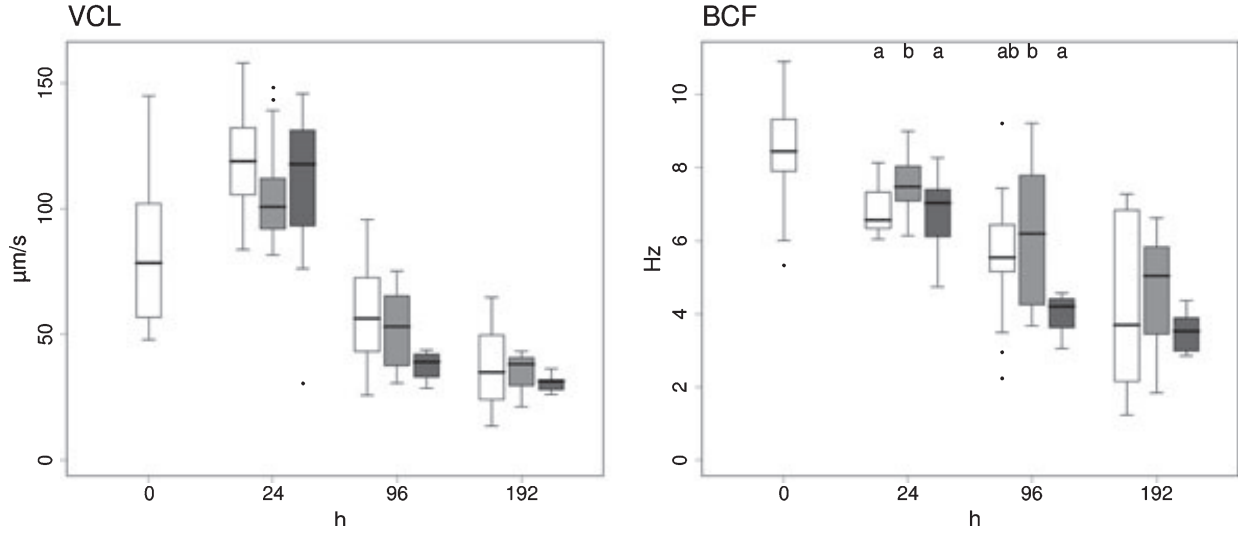

Fig. 1. Motility parameters assessed by CASA for the three treatments along time (white: Control; light grey: VitC; dark grey: EP). Different letters indicate significant differences $(\mathrm{p}<0.05)$ after a pairwise comparison within each time. The boxes spread from the 1 st to the $3 r d$ quartiles, the whiskers extend to the interquartile range $\times 1.5$, and the horizontal line indicates the median. Outliers are represented by dots 

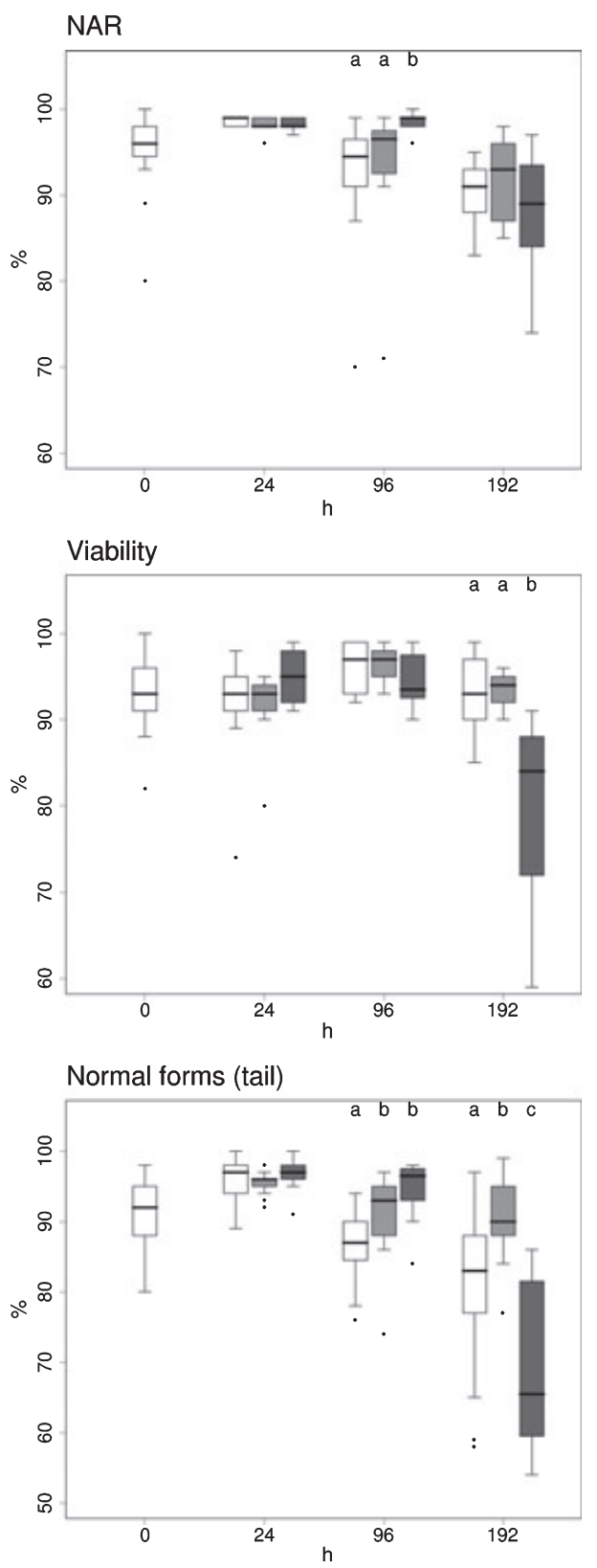

Fig. 2. Acrosomal status (NAR), viability and $\%$ of normal tails for the three treatments along time (white: Control; light grey: VitC; dark grey: EP). Different letters indicate significant differences $(\mathrm{p}<0.05)$ after a pairwise comparison within each time. The boxes spread from the 1st to the 3rd quartiles, the whiskers extend to the interquartile range $\times 1.5$, and the horizontal line indicates the median. Outliers are represented by dots

short-term (higher LIN and BCF, and lower ALH at $24 \mathrm{~h}$ ), whereas EP seemed to present lower parameters at $96 \mathrm{~h}$ (LIN and BCF).

Microscopy-assessed parameters were differently affected by storage treatments (Fig. 2). Acrosomal status seemed not to be specially preserved by any treatment. There were not great changes in general for sperm viability as assessed by the eosine-nicrosine staining, as the model indicated no effect of time in this parameter, but for EP samples, for which a drop was significantly found at $192 \mathrm{~h}$. Maybe related to that, we found a similar drop in normal forms for EP samples at the same sampling time. In this case, normal forms slowly decreased with time, but VitC partially prevented this decrease. Interestingly, storing the samples in the epididymis seemed to prevent too the occurrence of abnormal tails at least till $96 \mathrm{~h}$ sampling.

The SCSA analysis showed that both VitC and EP helped protecting chromatin in the long term (Fig. 3). SD-DFI and \%DFI increased with time from nearly 0 (non significant intercept), but slowly. The interaction of VitC and EP with time was significant and negative, showing that this increase was even slower in these treatments. In fact, at $192 \mathrm{~h}$, we found significant differences between Control and the treatments (at
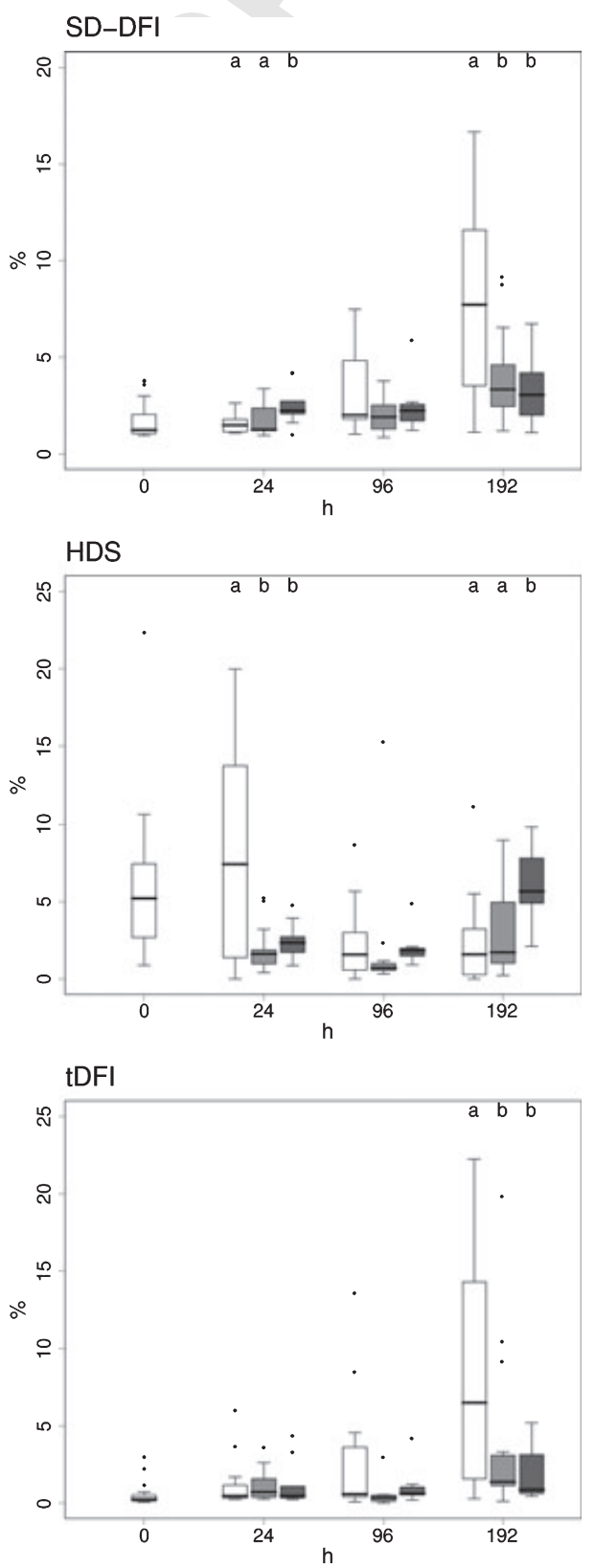

Fig. 3. Chromatin status (SCSA) for the three treatments along time (white: Control; light grey: VitC; dark grey: EP). Different letters indicate significant differences $(\mathrm{p}<0.05)$ after a pairwise comparison within each time. The boxes spread from the 1 st to the 3 rd quartiles, the whiskers extend to the interquartile range $\times 1.5$, and the horizontal line indicates the median. Outliers are represented by dots 
$24 \mathrm{~h}$ there was a transient higher SD-DFI for EP samples). HDS was significantly higher at $24 \mathrm{~h}$ for Control, and its distribution became very wide, but at

$996 \mathrm{~h}$ it returned to values similar to VitC and EP. HDS distribution was wider at $192 \mathrm{~h}$ for all treatments, and this parameter was significantly higher for EP at that time.

An important fact is that there were few differences between measures at 0 and $24 \mathrm{~h}$. Only MP (higher for VitC and lower for EP), LIN (higher for VitC and lower for Control) and BCF (lower for EP) showed significant differences for that sampling time.

\section{Discussion}

The cauda epididymides of live animals provide an excellent environment for sperm storage. Sperm mature as they pass through the caput and corpus of the epidymis and, once in the caudal portion, sperm may be held naturally in this segment for extended times. In this situation, spermatozoa retain their motility and fertilizing capacity (Young 1931).

However, it is generally assumed that gametes within the body of animals degenerate quickly after death. However, many studies have demonstrated that spermatozoa recovered from post-mortem specimens, even may hours after death, retained their function (Sankai et al. 1997; An et al. 1999; Kaabi et al. 2003; Soler et al. 2005). Indeed, in early studies of our own group we noticed that when testes of red deer after death are conserved by refrigeration $\left(5^{\circ} \mathrm{C}\right)$, sperm remain for extended periods viable and post-mortem changes are minimized by storage at this temperature (Soler et al. 2003). Although these earlier results are valuable for developing protocols to improve red deer spermatozoa survival after the animal death, there has been no other effort to find other alternatives to this situation. Moreover, sperm from epididymides are known to be susceptible to cold shock (White 1993).

One of the reasons storage temperature is critical may be due to the damage caused by reactive oxygen species (ROS), which leads to the event called 'oxidative stress' (Nichi et al. 2007). Epididymal samples are particularly susceptible to attack by ROS, as they are not exposed to the complex secretions of the accessory sex glands (seminal plasma), which are recognized as the prime source of anti-oxidant protection (Chen et al. 2003). Therefore, sperm characteristics after testes storage at $5^{\circ} \mathrm{C}$ could be better preserved if the effects caused by 'oxidative stress' are minimized. In this sense, many studies have noted the beneficial effects of vitamin C supplementation on sperm characteristics (Fraga et al. 1991; Yousef et al. 2003; Silver et al. 2005). However, only few studies have been aimed at investigating whether vitamin $\mathrm{C}$ supplementation in vitro could improve sperm survival during refrigeration (Donnelly et al. 1999; Ball et al. 2001).

In the present study, adding ascorbic acid helped to preserve linear movement at the short-term (higher progressive motility, LIN and BCF and lower ALH at $24 \mathrm{~h}$ ). These findings agree with those obtained by Eskenazi et al. (2005) who demonstrated that the anti- oxidant oral intake is associated with better semen quality, in particular, motility. Our results also revealed that refrigerated storage of testicles better preserved total motility. In fact, after $192 \mathrm{~h}$ of incubation, there was no motility in VitC samples, but in Control and storage of testicles, most samples had some motility. This result is consistent with the observations of Ball et al. (2001), who demonstrated that supplementation with vitamin $\mathrm{C}$ did not improve the maintenance of motility of cooled equine spermatozoa during 96-h storage, although in that study, there were no previous evaluations to 96-h. The possible beneficial effect of ascorbic acid during storage could not be demonstrated in sperm characteristics unless long time storage aspects were tested because, as Kankofer et al. (2005) reported, the antioxidative activity in both native and extended semen are maintained over $24 \mathrm{~h}$ storage at $5^{\circ} \mathrm{C}$. Therefore, we could expect that exogenous anti-oxidant protection was not necessary during short term storage, but for longer times, anti-oxidant could avoid bad effects of oxidative stress.

The most important finding of our study is the relationship between ascorbic acid supplementation and sperm DNA integrity during refrigerated storage, showing that Vitamin $\mathrm{C}$ protected sperm chromatin in vitro. Increased DFI has been associated with increased risk of miscarriage and increased time to pregnancy in humans (Larson et al. 2000; Evenson et al. 2002) and bulls and mice (Evenson et al. 1980; Ballachey et al. 1988). However, whereas there is some evidence that vitamin $\mathrm{C}$ intake may reduce DNA strand breaks (Green et al. 1994) and DNA base oxidation (Duthie et al. 1996) in human lymphocytes, there has been little research on the protective effect of ascorbic acid on sperm DNA (Ball et al. 2001). We have to consider that increased oxidative damage to sperm DNA has been associated with low ascorbic acid concentrations in seminal fluid (Fraga et al. 1991, 1996), and infertile males were found to have low ascorbic acid levels in seminal plasma (Dawson et al. 1992). Interestingly, Song et al. (2006) found that patients with low levels of seminal ascorbic acid had increased sperm DNA damage. Moreover, Fraga et al. (1991) demonstrated that ascorbic acid protects against endogenous oxidative DNA damage in human sperm. These authors also indicated that low ascorbic acid was associated with increased DNA damage even though no effect on sperm quality was observed, agreeing with our results. However, most of the studies of ascorbic acid on sperm characteristics have consisted of dietary supplementation and at the moment there is little information about the effects of ascorbic acid supplementation in vitro. Hughes et al. (1998) reported that in vitro treatment of sperm with ascorbic acid (300 and $600 \mu \mathrm{M})$ reduced the magnitude of DNA damage as measured by the Comet assay, and agreeing with our results.

Interestingly, in our experiment, testes storage (EP) seemed to protect chromatin as effectively as VitC. The present work seems to indicate that the endogenous anti-oxidant system of epididymes is capable for sustaining DNA protection. These observations are in 
agreement with other studies which showed that the protective mechanisms are indeed present in the sperm cells as well as in the epididymal fluid (Hinton et al. 1995). Data available for epididymal spermatozoa demonstrate that they are equipped with enzymatic mechanisms that can dispose of potentially harmful ROS (Tramer et al. 1998).

Besides, we found differences between our treatments regarding HDS. HDS data is interesting, because this parameter has been related to sperm chromatin maturity (Evenson and Wixon 2006). Although HDS was high at $24 \mathrm{~h}$ in the Control samples, it lowered at subsequent times, whereas it remained low in VitC and EP samples, at least till $96 \mathrm{~h}$. Since we were working with epididymal spermatozoa, it is possible that dilution and storage induced these changes in the chromatin, maybe related to maturation, thus the higher HDS at $24 \mathrm{~h}$ in the Control, while further incubation would reverse these changes. In contrast, an anti-oxidant environment or the epididymal environment would prevent them. The increase of HDS in VitC and EP observed at $196 \mathrm{~h}$ may indicate that these treatments simply delayed the changes observed in the Control at $24 \mathrm{~h}$, and it is possible that anti-oxidant consumption or general decay in the epididymis triggered these events at advanced storage time.

In conclusion, our study showed that refrigerated storage of epididymal spermatozoa from red deer may be improved either by refrigerating the testicles and collecting the sample just before freezing, or by diluting the spermatozoa in a medium supplemented with vitamin C. These findings are especially interesting regarding its practical use in the field, when it is not possible to take up immediate freezing of post-mortem samples. It is important to note that motility was preserved better in VitC at $24 \mathrm{~h}$, therefore, when freezing can be carried out within few hours after harvesting the genital, the better option would be extracting and diluting the sperm sample in a medium with anti-oxidants.

Nevertheless, none of the treatments was able to maintain sperm quality in prolonged storage. However, when a very valuable male dies and it is not possible to freeze the sperm until several days later, we have still the 10 option of freezing the sample for trying in vitro 11 fertilization (IVF) or intracytoplasmic sperm injection (ICSI). In this case, just storing the genital would be the more convenient option, since we have observed that chromatin status, possibly the most important characteristic when using in vitro techniques, is preserved as well as when diluting in an anti-oxidant-supplemented medium. Nevertheless, we must take into account that some parameters (viability, normal tails) were lower in epididymal samples at the most prolonged time, and the significance of HDS increase in these samples must be still assessed. Although there are some studies regarding post-mortem storage and IVF or fertility success (Kikuchi et al. 1998; Kishikawa et al. 1999), they have not been related to chromatin status at post-mortem times. Thus, a further step in our research would be to test if the differences we have found at prolonged storage times are indeed reflected in IVF or ICSI success.

\section{Acknowledgements}

This work has been supported by the Spanish Ministry of Education and Science (Project AGL2004-05904/GAN). Felipe Martínez-Pastor was supported by the Juan de la Cierva program (Spanish Ministry of Education and Science).

\section{References}

Agarwal A, Nallella KP, Allamaneni SS, Said TM, 2004: Role of antioxidants in treatment of male infertility: an overview of the literature. Reprod Biomed Online 8, 616-627.

An TZ, Wada S, Edashige K, Sakurai T, Kasai M, 1999: Viable spermatozoa can be recovered from refrigerated mice up to 7 days after death. Cryobiology 38, 27-34.

Ball BA, Medina V, Gravance CG, Baumbe J, 2001: Effect of antioxidants on preservation of motility, viability and acrosomal integrity of equine spermatozoa during storage at $5^{\circ} \mathrm{C}$. Theriogenology 56, 577-589.

Ballachey BE, Evenson DP, Saacke RG, 1988: The sperm chromatin structure assay. Relationship with alternate tests of semen quality and heterospermic performance of bulls. $\mathbf{J}$ Androl 9, 109-115.

Chen H, Chow PH, Cheng SK, Cheung AL, Cheng LY, WS O, 2003: Male genital tract antioxidant enzymes: their source, function in the female, and ability to preserve sperm DNA integrity in the golden hamster. J Androl 24, 704-711.

Comizzoli P, Mauget R, Mermillod P, 2001: Assessment of in vitro fertility of deer spermatozoa by heterologous IVF with zona-free bovine oocytes. Theriogenology 56, 261-274.

Dawson EB, Harris WA, Teter MC, Powell LC, 1992: Effect of ascorbic acid supplementation on the sperm quality of smokers. Fertil Steril 58, 1034-1039.

Donnelly ET, McClure N, Lewis SE, 1999: Antioxidant supplementation in vitro does not improve human sperm motility. Fertil Steril 72, 484-495.

Duthie SJ, Ma A, Ross MA, Collins AR, 1996: Antioxidant supplementation decreases oxidative DNA damage in human lymphocytes. Cancer Res 56, 1291-1295.

Eskenazi B, Kidd SA, Marks AR, Sloter E, Block G, Wyrobek AJ, 2005: Antioxidant intake is associated with semen quality in healthy men. Hum Reprod 20, 1006-1012.

Evenson DP, Wixon R, 2006: Clinical aspects of sperm DNA fragmentation detection and male infertility. Theriogenology 65, 979-991.

Evenson DP, Darzynkiewicz Z, Melamed MR, 1980: Relation of mammalian sperm chromatin heterogeneity to fertility. Science 210, 1131-1133.

Evenson DP, Larson KL, Jost LK, 2002: Sperm chromatin structure assay: its clinical use for detecting sperm DNA fragmentation in male infertility and comparisons with other techniques. J Androl 23, 25-43.

Fernandez-Santos MR, Esteso MC, Montoro V, Soler AJ, Garde JJ, 2006a: Influence of various permeating cryoprotectants on freezability of Iberian red deer (Cervus elaphus hispanicus) epididymal spermatozoa: effects of concentration and temperature of addition. J Androl 27, 734-745.

Fernandez-Santos MR, Esteso MC, Soler AJ, Montoro V, Garde JJ, 2006b: Effects of egg yolk and cooling rate on the survival of refrigerated red deer (Cervus elaphus hispanicus) epididymal spermatozoa. Reprod Domest Anim 41, 114-118.

Fernandez-Santos MR, Martinez-Pastor F, Garcia-Macias V, Esteso MC, Soler AJ, Paz P, Anel L, Garde JJ, 2007a: Extender osmolality and sugar supplementation exert a complex effect on the cryopreservation of Iberian red deer (Cervus elaphus hispanicus) epididymal spermatozoa. Theriogenology 67, 738-753. 
Fernandez-Santos MR, Martinez-Pastor F, Garcia-Macias V, Esteso MC, Soler AJ, Paz P, Anel L, Garde JJ, 2007b: Sperm characteristics and DNA integrity of Iberian red deer (Cervus elaphus hispanicus) epididymal spermatozoa frozen in the presence of enzymatic and nonenzymatic antioxidants. J Androl 28, 294-305.

Fraga CG, Motchnik PA, Shigenaga MK, Helbock HJ, Jacob RA, Ames BN, 1991: Ascorbic acid protects against endogenous oxidative DNA damage in human sperm. Proc Natl Acad Sci USA 88, 11003-11006.

Fraga CG, Motchnik PA, Wyrobek AJ, Rempel DM, Ames BN, 1996: Smoking and low antioxidant levels increase oxidative damage to sperm DNA. Mutat Res 351, 199-203.

Green MH, Lowe JE, Waugh AP, Aldridge KE, Cole J, Arlett CF, 1994: Effect of diet and vitamin C on DNA strand breakage in freshly-isolated human white blood cells. Mutat Res 316, 91-102.

Halliwell B, 1991: Reactive oxygen species in living systems: source, biochemistry, and role in human disease. Am J Med 91, 14S-22S.

Hinton BT, Palladino MA, Rudolph D, Labus JC, 1995: The epididymis as protector of maturing spermatozoa. Reprod Fertil Dev 7, 731-745.

Hishinuma M, Suzuki K, Sekine J, 2003: Recovery and cryopreservation of sika deer (Cervus nippon) spermatozoa from epididymides stored at $4{ }^{\circ} \mathrm{C}$. Theriogenology 59, 813-820.

Holt WV, Abaigar T, Jabbour HN, 1996: Oestrous synchronization, semen preservation and artificial insemination in the Mohor gazelle (Gazella dama mhorr) for the establishment of a genome resource bank programme. Reprod Fertil Dev 8, 1215-1222.

Hughes CM, Lewis SE, Kelvey-Martin VJ, Thompson W, 1998: The effects of antioxidant supplementation during Percoll preparation on human sperm DNA integrity. Hum Reprod 13, 1240-1247.

Januskauska A, Johannisson A, Rodriguez-Martinez H, 2001: Assessment of sperm quality through fluorometry and sperm chromatin structure assay in relation to field fertility of frozen-thawed semen from Swedish AI bulls. Theriogenology 55, 947-961.

Kaabi M, Paz P, Alvarez M, Anel E, Boixo JC, Rouissi H, Herraez P, Anel L, 2003: Effect of epididymis handling conditions on the quality of ram spermatozoa recovered post-mortem. Theriogenology 60, 1249-1259.

Kankofer M, Kolm G, Aurich J, Aurich C, 2005: Activity of glutathione peroxidase, superoxide dismutase and catalase and lipid peroxidation intensity in stallion semen during storage at $5^{\circ} \mathrm{C}$. Theriogenology 63, 1354-1365.

Kikuchi K, Nagai T, Kashiwazaki N, Ikeda H, Noguchi J, Shimada A, Soloy E, Kaneko H, 1998: Cryopreservation and ensuing in vitro fertilization ability of boar spermatozoa from epididymides stored at $4^{\circ} \mathrm{C}$. Theriogenology $\mathbf{5 0}$, $615-623$

Kishikawa H, Tateno H, Yanagimachi R, 1999: Fertility of mouse spermatozoa retrieved from cadavers and maintained at $4^{\circ} \mathrm{C}$. J Reprod Fertil 116, 217-222.

Larson KL, DeJonge CJ, Barnes AM, Jost LK, Evenson DP, 2000: Sperm chromatin structure assay parameters as predictors of failed pregnancy following assisted reproductive techniques. Hum Reprod 15, 1717-1722.

Lewis SE, Sterling ES, Young IS, Thompson W, 1997: Comparison of individual antioxidants of sperm and seminal plasma in fertile and infertile men. Fertil Steril 67, 142-147.

Martinez-Pastor F, Guerra C, Kaabi M, Diaz AR, Anel E, Herraez P, Paz P, Anel L, 2005a: Decay of sperm obtained from epididymes of wild ruminants depending on postmortem time. Theriogenology 63, 24-40.
Martinez-Pastor F, Díaz-Corujo AR, Anel E, Herraez P, Anel L, Paz P, 2005b: Post mortem time and season alter subpopulation characteristics of Iberian red deer epididymal sperm. Theriogenology 64, 958-974.

Martinez-Pastor F, Anel L, Guerra C, Alvarez M, Soler AJ, Garde JJ, Chamorro C, Paz P, 2006: Seminal plasma improves cryopreservation of iberian red deer epididymal sperm. Theriogenology 66, 1847-1856.

Maxwell WM, Salamon S, 1993: Liquid storage of ram semen: a review. Reprod Fertil Dev 5, 613-638.

Maxwell WM, Stojanov T, 1996: Liquid storage of ram semen in the absence or presence of some antioxidants. Reprod Fertil Dev 8, 1013-1020.

Millar J, 1992: Vitamin C, the primate fertility factor? Med Hypotheses 38, 292-295.

Misra HP, Fridovich I, 1972: The univalent reduction of oxygen by reduced flavins and quinones. J Biol Chem $\mathbf{2 4 7}$, 188-192.

Nichi M, Goovaerts IG, Cortada CN, Barnabe VH, De Clercq JB, Bols PE, 2007: Roles of lipid peroxidation and cytoplasmic droplets on in vitro fertilization capacity of sperm collected from bovine epididymides stored at 4 and $34^{\circ} \mathrm{C}$. Theriogenology 67, 334-340.

Pinheiro JC, Bates DM, 2000: Mixed-Effects Models in S and S-Plus. Springuer-Verlag, ??????????????

Sankai T, Shimizu K, Cho F, Yoshikawa Y, 1997: In vitro fertilization of follicular oocytes by frozen-thawed spermatozoa in Japanese monkeys (Macaca fuscata). Lab Anim Sci 47, 58-62.

Silver EW, Eskenazi B, Evenson DP, Block G, Young S, Wyrobek AJ, 2005: Effect of antioxidant intake on sperm chromatin stability in healthy nonsmoking men. J Androl 26, 550-556.

Soler AJ, Perez-Guzman MD, Garde JJ, 2003a: Storage of red deer epididymides for four days at $5{ }^{\circ} \mathrm{C}$ : Effects on sperm motility, viability, and morphological integrity. J Exp Zoolog 295, 188-199.

Soler AJ, Astore V, Sestelo A, Rivolta M, Jacome LN, Garde JJ, 2003b: Effect of thawing procedure on cryosurvival of deer spermatozoa: work in progress. Theriogenology 60 , 511-520.

Soler AJ, Esteso MC, Fernandez-Santos MR, Garde JJ, 2005: Characteristics of Iberian red deer (Cervus elaphus hispanicus) spermatozoa cryopreserved after storage at $5{ }^{\circ} \mathrm{C}$ in the epididymis for several days. Theriogenology 64, 1503-1517.

Song GJ, Norkus EP, Lewis V, 2006: Relationship between seminal ascorbic acid and sperm DNA integrity in infertile men. Int J Androl 29, 569-575.

Songsasen N, Tong J, Leibo SP, 1998: Birth of live mice derived by in vitro fertilization with spermatozoa retrieved up to twenty-four hours after death. J Exp Zool 280, 189-196.

Tamuli M, Watson PF, 1994: Use of simple staining technique to distinguish acrosomal changes in the live sperm subpopulation. Anim Reprod Sci ????, 247-254.

Tramer F, Rocco F, Micali F, Sandri G, Panfili E, 1998: Antioxidant systems in rat epididymal spermatozoa. Biol Reprod 59, 753-758.

Upreti GC, Jensen K, Oliver JE, Duganzich DM, Munday R, Smith JF, 1997: Motility of ram spermatozoa during storage in a chemically-defined diluent containing antioxidants. Anim Reprod Sci 48, 269-278.

Upreti GC, Jensen K, Munday R, Duganzich DM, Vishwanath R, Smith JF, 1998: Studies on aromatic amino acid oxidase activity in ram spermatozoa: role of pyruvate as an antioxidant. Anim Reprod Sci 51, 275-287.

White IG, 1993: Lipids and calcium uptake of sperm in relation to cold shock and preservation: a review. Reprod Fertil Dev 5, 639-658. 
Young WC, 1931: A study of the function of the epididymis III. Functional changes undergone by spermatozoa during their passage through the epididymis and vas deferens in the ginea-pig. J Exp Biol 8, 151-162.

Yousef MI, Abdallah GA, Kamel KI, 2003: Effect of ascorbic acid and Vitamin E supplementation on semen quality and biochemical parameters of male rabbits. Anim Reprod Sci 76, 99-111.

Yu I, Leibo SP, 2002: Recovery of motile, membrane-intact spermatozoa from canine epididymides stored for 8 days at $4^{\circ} \mathrm{C}$. Theriogenology 57, 1179-1190.
Zomborszky Z, Zubor T, Toth J, Horn P, 1999: Sperm collection from shot red deer stags (Cervus elaphus) and the utilisation of sperm frozen and subsequently thawed. Acta Vet Hung 47, 263-270.

Submitted: 27.09 .2007

Author's address (for correspondence): F Martínez-Pastor, National Wildlife Research Institute (IREC), UCLM-CSIC-JCCM. Av. de España, 02071 Albacete, Spain. E-mail: felipe.martínez@uclm.es 


\section{Author Query Form}

Journal: RDA

Article: $\quad 1032$

Dear Author,

During the copy-editing of your paper, the following queries arose. Please respond to these by marking up your proofs with the necessary changes/additions. Please write your answers on the query sheet if there is insufficient space on the page proofs. Please write clearly and follow the conventions shown on the attached corrections sheet. If returning the proof by fax do not write too close to the paper's edge. Please remember that illegible mark-ups may delay publication.

Many thanks for your assistance.

\begin{tabular}{|c|c|c|}
\hline $\begin{array}{l}\text { Query } \\
\text { reference }\end{array}$ & Query & Remarks \\
\hline Q1 & Au: May please check the correctness of expansion of CASA. & \\
\hline Q2 & $\begin{array}{l}\text { Au: May please check the correctness of expansion of abbreviated form of } \\
\text { SCSA. }\end{array}$ & \\
\hline Q3 & Au: May please check whether this is what is meant by you. & \\
\hline Q4 & Au: May please check whether this is what you meant. & \\
\hline Q5 & Au: May please check whether this is what you meant. & \\
\hline Q6 & $\begin{array}{l}\text { Au: Please provide manufacturer information for CASA system: company } \\
\text { name, town, state (if USA) and country. }\end{array}$ & \\
\hline Q7 & $\begin{array}{l}\text { Au: Please provide manufacturer information for Nikon Eclipse 80i: company } \\
\text { name, town, state (if USA) and country. }\end{array}$ & \\
\hline Q8 & Au: Please check this website address and confirm that it is correct. & \\
\hline Q9 & Au: May please check whether this is what you meant. & \\
\hline Q10 & Au: May please check. & \\
\hline Q11 & Au: May please check whether this is what was meant by you. & \\
\hline Q12 & Au: Please provide publisher address in reference Pinheiro, Bates (2000). & \\
\hline Q13 & Au: Please check journal title for this reference. & \\
\hline Q14 & Au: Please provide volume number in reference Tamuli, Watson (1994). & \\
\hline
\end{tabular}




\section{Please correct and return this set}

Please use the proof correction marks shown below for all alterations and corrections. If you wish to return your proof by fax you should ensure that all amendments are written clearly in dark ink and are made well within the page margins.

\begin{tabular}{|c|c|c|}
\hline Instruction to printer & Textual mark & Marginal mark \\
\hline Leave unchanged & ... under matter to remain & ( ) \\
\hline $\begin{array}{l}\text { Insert in text the matter } \\
\text { indicated in the margin }\end{array}$ & $h$ & $\begin{array}{l}\text { New matter followed by } \\
h \text { or } h \otimes\end{array}$ \\
\hline Delete & $\begin{array}{l}\text { I through single character, rule or underline } \\
\text { or }\end{array}$ & $\sigma$ or $\sigma(x)$ \\
\hline $\begin{array}{l}\text { Substitute character or } \\
\text { substitute part of one or } \\
\text { more word(s) }\end{array}$ & I through letter or & $\begin{array}{l}\text { new character / or } \\
\text { new characters / }\end{array}$ \\
\hline Change to italics & — under matter to be changed & $\leftarrow$ \\
\hline Change to capitals & $\equiv$ under matter to be changed & $\equiv$ \\
\hline Change to small capitals & $=$ under matter to be changed & $=$ \\
\hline Change to bold type & $\sim$ under matter to be changed & $\sim$ \\
\hline Change to bold italic & $\bar{\sim}$ under matter to be changed & $\underline{s i n}$ \\
\hline Change to lower case & Encircle matter to be changed & $\Rightarrow$ \\
\hline Change italic to upright type & (As above) & \\
\hline Change bold to non-bold type & (As above) & \\
\hline Insert 'superior' character & $\begin{array}{l}/ \text { through character or } \\
K \text { where required }\end{array}$ & $\begin{array}{l}y^{\prime} \text { or } y \\
\text { under character } \\
\text { e.g. } y^{2} \text { or } y^{2}\end{array}$ \\
\hline Insert 'inferior' character & (As above) & $\begin{array}{l}\lambda \\
\text { over character } \\
\text { e.g. } \hat{\Sigma}\end{array}$ \\
\hline Insert full stop & (As above) & $\odot$ \\
\hline Insert comma & (As above) & , \\
\hline Insert single quotation marks & (As above) & $\begin{array}{l}\dot{y} \text { or } \dot{x} \text { and/or } \\
\dot{y} \text { or } \dot{y}\end{array}$ \\
\hline Insert double quotation marks & (As above) & $\begin{array}{l}\ddot{y} \text { or } \ddot{y} \text { and/or } \\
\ddot{y} \text { or } \ddot{y}\end{array}$ \\
\hline Insert hyphen & (As above) & 1 \\
\hline Start new paragraph & 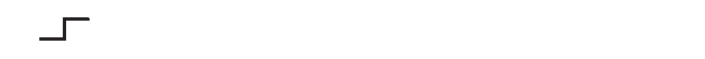 & 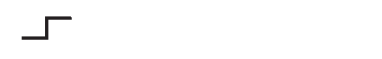 \\
\hline No new paragraph & $\infty$ & $\omega$ \\
\hline Transpose & $\sqcup$ & $\sqcup$ \\
\hline Close up & linking $\bigcirc$ characters & \\
\hline $\begin{array}{l}\text { Insert or substitute space } \\
\text { between characters or words }\end{array}$ & $\begin{array}{l}\text { I through character or } \\
\Lambda \text { where required }\end{array}$ & \\
\hline $\begin{array}{l}\text { Reduce space between } \\
\text { characters or words }\end{array}$ & $\begin{array}{l}\text { between characters or } \\
\text { words affected }\end{array}$ & $\uparrow$ \\
\hline
\end{tabular}

